\title{
COMBATE À CORRUPÇÃO E O COMPLIANCE NA AMÉRICA LATINA
}

Felipe D. Martarelli Fernandes ${ }^{1}$

Recebido em 01/07/2021

Aceito em 16/08/2021

\section{RESUMO}

O instituto do compliance está intrinsicamente ligado ao combate da corrupção, trata-se de um instrumento interno da pessoa jurídica em parceria com as autoridades estatais a fim de evitar a corrupção corporativa, como a lavagem de dinheiro, subornos e fraudes em licitações, tal instituto tem aplicação recente na América Latina, onde deve ser estudado de maneira internacional a fim de abranger todos os países da região.

PALAVRAS CHAVE: Compliance. Corrupção. América Latina. Direito Internacional.

Lavagem de Dinheiro. Suborno.

\section{THE FIGHT AGAINST CORRUPTION AND COMPLIANCE IN LATIN AMERICA}

\section{ABSTRACT}

The compliance institute is intrinsically linked to the fight against corruption; it is an internal legal entity instrument in partnership with state authorities to prevent corporate corruption, such as money laundering, bribery and fraud in biddings, such an institute has a recent application in Latin America, where it must be studied in order to cover all the countries of the region.

Keywords: Compliance. Corruption. Latin America. International right. Money laundry.

\section{INTRODUÇÃO}

O presente trabalho visará o entendimento sobre o instituto do compliance e sua direta ligação com a corrupção presente nas pessoas jurídicas de direito público e privado, com foco principal, na prática do suborno como ato corruptivo.

Assim, será igualmente demonstrado as profundas consequências sociais que a corrupção causa nos países em desenvolvimento e sua minoração em relação aos países que aplicam efetivamente o compliance.

Neste mesmo sentido, será trabalhado a correlação da participação dos órgãos na

\footnotetext{
${ }^{1}$ Advogado, Professor na Universidade Anhembi Morumbi, Coordenador do Núcleo de Práticas jurídicas UAM, especialista em processo civil pela PUC/SP, Mestre em Direitos Fundamentais pela UniFieo, Doutorando em Direito Constitucional pela Faculdade Autônoma de Direito - FADISP e Bolsista CAPES. Email:felipemartarelli@adv.oabsp.org.br.
} 
elucidação de eventuais problemas e fiscalização interna a fim de trazer para a sociedade a transparência necessária para o bom desenvolvimento social.

Será estudada a origem do compliance, assim como a sua aplicabilidade na América Latina, demonstrando-se, portanto, a necessidade da utilização internacional deste instituto, uma vez que a sua utilização nacional se torna quase que ineficaz.

Posteriormente, será demonstrado que a aplicabilidade do compliance refuta, retarda ou diminui a corrupção institucionalizada, gerando para a sociedade frutos e evitando danos, muitas vezes irreparáveis, ao Estado.

Por fim, serão verificadas as normas internacionais que regem e atuam em grande parte da América Latina, a fim de combater a corrupção empresarial sistêmica, sua possível solução e consequências sociais.

\section{COMPLIANCE E SUA RECEPÇÃO PELO ESTADO BRASILEIRO}

$\mathrm{O}$ instituto do compliance tem origem norte americana e possui pelo menos três finalidade inerentes. A primeira, a qual o presente trabalho irá focar-se, tem como conceito central programas para combater a corrupção dentro das instituições jurídicas, a fim de evitar atos corruptivos, como a lavagem de dinheiro, subornos e fraudes fiscais, trazendo para uma maior transparência perante o mercado, facilidade de fiscalização interna quanto externa e eficácia na aplicabilidade de eventuais sanções. Neste sentido entende Márcio Adriano Anselmo quando relata que "seu significado é bastante simples, podendo ser definido como em conformidade com leis e regulamentos, passando a assumir notoriedade com os programas de compliance relacionados ao sistema financeiro e programas anticorrupção"2.

A segunda função inerente que o compliance possui é de instrumentalizar a dignidade da pessoa humana no âmbito da pessoa jurídica, quando adequa as condutas dos sujeitos internos ao regramento ético e moral necessário, sob pena de sanções administrativas, sendo estas fiscalizadas por órgãos de compliance internos ou empresas externas especializadas em compliance. Por fim, a terceira função inerente do compliance é a valoração da pessoa jurídica no mercado financeiro.

Como exposto o presente trabalho focará na primeira função inerente do compliance, qual seja a de combate aos atos corruptivos da pessoa jurídica, neste diapasão a ideia posta é que as pessoas jurídicas, de direito privado ou de direito público, atuem obedecendo todas as

\footnotetext{
${ }^{2}$ ANSELMO, Márcio Adriano. Compliance, direito penal e investigação criminal: uma análise à luz da ISSO 19600 e 37001, Revista dos Tribunais, vol. 979, ano 106. p.53-67. São Paulo: Ed RT, 2017. p.53/54.
} 
normas e leis estabelecidas pelos Estados em que se encontram, empreendendo e atuando não somente com eficácia, mas também com todo respaldo jurídico necessário para uma atuação que gere confiança no mercado baseado na ética e evitando sanções por parte do Estado e do próprio mercado financeiro.

O termo compliance começou a ser utilizado no início do século XX nos EUA, porém, foi somente na década de 1970, com a Foreign Corrupt Practices Act ${ }^{3}$, que o instituto começou a tomar as formas que possui hoje em dia, ou seja, após evidentes casos de corrupção, que por séculos lesaram os Estados Unidos, como foram os casos "Credit Mobilier" $\mathrm{e}$ "Watergate", foi desenvolvido um instrumento interno às pessoas jurídicas a fim de autofiscalização, com caráter de confiabilidade e eficácia.

Salienta-se, contudo, que em julho de 2020 a Foreign Corrupt Practices Act ${ }^{5}$, recebeu uma nova atualização pelo Departamento de Justiça Norte Americano, aumentando a rigidez na fiscalização contra a corrupção das pessoas jurídicas, tal atualização faz com que o Estado Norte Americano traga para si responsabilidades por atos corruptivos, como por exemplo o suborno, em face de agentes americanos, mesmo estando estes em solo estrangeiro.

O compliance deve ser cosmopolita tanto quanto o imperativo categórico de Immanuel $\mathrm{Kant}^{6}$, ou seja, para que haja sua devida efetividade se faz necessário que as regras, fiscalizações e condutas a serem seguidas, possam ser aplicadas ainda que efetuadas fora do território pátrio, uma vez que perderá a eficácia caso a pessoa jurídica pertença também a outro território, isto na hipótese de ser restrita a um único Estado

Ainda no âmbito internacional, foram criadas as normas de gestão de compliance (ISO 19600:2014) e norma anticorrupção (ISO 37001:2016), as quais tentam, de maneira uniforme, aplicar a regra para diversos países, inclusive Márcio Adriano Anselmo diz que "no âmbito internacional, um dos temas mais recentes diz respeito a instituição nas normas ISO 19600:2014 e ISO 37001:2016, que cria um padrão global para gerenciamento e avaliação dos programas de compliance e anticorrupção"7, como será demonstrado mais à frente.

No Brasil, o termo compliance também nasce ligado ao mundo empresarial e econômico, todavia, logo encontra necessidade de discussão na esfera penal, sendo seu

\footnotetext{
${ }^{3}$ Foreign Corrupt Practices Act, Disponível em : < https://www.justice.gov/criminal-fraud/fcpa-resource-guide > , Acesso em 11 de nov. 2020.

${ }^{4}$ NOONAN JR, John T., Subornos, Tradução Elsa Martins, $1^{\text {a }}$ ed., Rio de Janeiro: Editora Betrand Brasil S.A., 1984. p. 589.

${ }^{5}$ Foreign Corrupt Practices Act, Disponível em : < https://www.justice.gov/criminal-fraud/fcpa-resource-guide > , Acesso em 11 de nov. 2020.

${ }^{6}$ KANT, Immanuel. Crítica da Razão Prática, $3^{\mathrm{a}}$ ed., São Paulo: Martin Claret, 2011. p. 31.

${ }^{7}$ ANSELMO, Márcio Adriano. Compliance, direito penal e investigação criminal: uma análise à luz da ISSO

19600 e 37001, Revista dos Tribunais, vol. 979, ano 106. p.53-67. São Paulo: Ed RT, 2017. p.55.
} 
momento embrionário o ano de 1998, ocasião em que foi promulgada a norma de combate à lavagem de dinheiro, a qual foi alterada em 2012 para dar uma redação mais acertada sobre o tema, tema que também será devidamente analisado e desenvolvido a posteriori, uma vez que a lavagem de dinheiro é uma modalidade de corrupção, assim como o suborno, portanto, devendo também ser fiscalizada e observada pelo compliance, a ser implementado pela pessoa jurídica.

Ao fiscalizar tais atos de corrupção, o compliance também aplica a ética, moral e a legalidade, a fim de fomentar uma melhor produtividade e possibilitando uma melhor qualidade de ambiente às pessoas ali engajadas. Neste diapasão, o compliance cumprindo todas as normas morais e legais assim impostas, demonstra uma confiabilidade perante o mercado de maneira a valorar-se e a sociedade em que atua.

Neste sentido, explicando tal valoração, Guilherme Lobo Marchioni afirma que "hoje as empresas sérias conhecem o conceito de compliance sua intrínseca relação com a ética corporativa. E mais, aquelas empresas que compreendem a necessidade de se adequarem à nova cultura do cumprimento de compliance ${ }^{8 "}$.

Vale ressaltar que, o instituto do compliance tratado no presente trabalho exige uma atuação da pessoa jurídica de autofiscalização interna, transparência e cooperação com as autoridades locais, devendo trabalhar em conjunto com aquela para dirimir e evidenciar quaisquer tipos de irregularidades.

No Brasil, assim como na América Latina, o compliance ainda não possui a efetividade que já tem em países desenvolvidos, porém, já está muito a quem, do que estivera no passado, assim, deve-se primeiramente tratar-se da norma brasileira lei ${ }^{\circ} 12.846 / 13$, a chamada de lei anticorrupção, a qual traz em seu bojo tratamento distinto para aquelas pessoas jurídicas que possuem um plano interno de compliance.

Tal norma, em seu artigo $7^{\circ}$, VIII, determina que a aplicabilidade da pena será ponderada sobre alguns fatos, entre eles: "a existência de mecanismos e procedimentos internos de integridade, auditoria e incentivo à denúncia de irregularidades e a aplicação efetiva de códigos de ética e de conduta no âmbito da pessoa jurídica". Evidencia-se que tal mudança no tratamento ocorre devido a aplicabilidade de um compliance, ou seja, caso a empresa mantenha, em caráter interno, meios que facilitem a demonstração e clareza de seus atos, possuirá uma

\footnotetext{
${ }^{8}$ MARCHIONI, Guilherme Lobo. Protagonismo isolado da ISO 19600 em compliance não é apropriado. Disponível em: https://www.conjur.com.br/2016-jul-29/guilherme-lobo-protagonismo-iso-compliance-naoapropriado. Acesso em 04 de mar.2019.

9 Lei anticorrupção - Disponível em: <http://www.planalto.gov.br/CCIVIL_03/_Ato20112014/2013/Lei/L12846.htm>. Acesso em: 05 mar. 2019.
} 
atenuante na aplicabilidade de sua pena nos casos concretos.

No mesmo sentido caminha a lei anticorrupção de $n^{\circ} 12.846$ publicada em 01.08.2013, a qual prevê sanções administrativas para empresas que se envolvam em corrupção, por mais que não se trate de norma de caráter penal, esta possui eficácia e se adequa à política de transparência das empresas.

Tal assunto evidencia-se no presente momento histórico tendo-se em vista a recessão que assola o Brasil desde o começo da presente década de maneira catastrófica, para Alexandre Baraldi Tonin

Aliada à gravidade da situação, vivenciada pelos brasileiros, diante de uma regressão no crescimento econômico favorecida pelos inúmeros casos de corrupção que assolam o país, surge a necessidade de rever o direito penal econômico no Brasil ${ }^{10}$.

Neste caso muitas empresas, a fim de melhorar sua imagem perante o mercado econômico, começam a deixar de maneira mais transparente boa parte de seus atos.

O foco central da publicidade como meio fiscalização é defendida em todas as áreas do direito, como por exemplo, os ensinamentos de Honoré Gabriel Riqueti de Mirabeau, que na revolução francesa enaltece o Princípio da Publicidade nos processos até a nossa Constituição, de 05 de outubro de 1988, porém, entende-se que também há muitas vezes um viés de marketing, como foi feito por muitas empresas no Brasil após escândalos de corrupção e neste sentido Renato de Mello Silveira entende que:

\footnotetext{
Passou-se então, explicitamente, a destacar o problema relacionado a temas de compliance. Algumas das maiores empresas brasileiras, aliás, encontrando-se envolvidas em operações bastante suspeitas, acabaram por elaborar complexos programas em compliance pós-delitivos, em busca de evidenciar, ao mercado e à justiça, sua decisão pontual de se ombrear contra qualquer atuação vista como irregular"11.
}

Nota-se, portanto, que um dos pontos fundamentais a ser tratado é que a falta de compliance em um órgão facilita a corrupção deste, atingindo diretamente a sociedade, uma vez que os valores destinados aos devidos recolhimentos de impostos, verbas trabalhistas, consumeristas, entre outras não são devidamente cumpridos.

Verifica-se que o dano, elencado nestes casos, é transcendental a um sujeito, não se trata

10 TONIN, Alexandre Baraldi. Compliance: Uma visão do compliance como forma de mitigação de responsabilidade. Revista dos Tribunais, Vol. 983. Ano.106. p.265-288. São Paulo, 2017.

${ }^{11}$ SILVEIRA, Renato de Mello Jorge. Compliance e direito penal na era pós-lava jato. Revista dos Tribunais. Vol. 979. Ano 106, p.31-52, São Paulo, 2017. 
de dano individual, mas sim da existência de um dano difuso, ou seja, todos de maneira indeterminável são atingidos, neste caminhar encontra o entendimento de Alexandre Badaldi Tonin:

Esse perfil de criminalidade é extremamente danoso para a sociedade, ao ponto de que milhares de reais são desviados, em esquemas de corrupção que retiram todo o poder de investimento do Estado, deixando este de primar pelas condições básicas e necessárias da sociedade, tais como saúde, educação e segurança. ${ }^{12}$

Seguindo a evolução do compliance no Brasil, a lei de $1^{\circ}$ de abril de 2021 , a chamada “nova lei de licitações e contratos administrativos", veio substituir a clássica norma 8.666/91, com o objetivo de uma maior regularização e fiscalização dos atos corruptivos.

Assim, a fim de combater as atividades corruptivas, tal norma trouxe em seu bojo, mais especificadamente em seu artigo $5^{\circ}$, princípios inerentes sobre a moralidade, transparência e desenvolvimento sustentável assim como em seu art. $25^{13}$, onde determina como obrigacional que qualquer empresa que tenha ganhado a licitação com o poder público possa de maneira efetiva, no prazo de 06 (seis) meses, criar programas de integridade efetivos, sob pena de aplicação de multa.

Nota-se que, mais do que valorizar a pessoa jurídica no mercado, o compliance tornase um instrumento de fiscalização e combate à corrupção necessário para que possa atuar conjuntamente com o poder público, diminuindo assim os atos lesivos à toda população.

Como já mencionado, evidencia-se, inclusive, que um mesmo ato lesivo empresarial pode se estender a causar um dano difuso, coletivo e individual homogêneo, causando distúrbio social, econômico e jurídico em diversas áreas da sociedade e nas palavras de Sérgio Shimura "um mesmo fato pode ensejar diferentes tipos de tutela, por ofender diversos tipos de interesse(...)" ${ }^{\prime 14}$. Portanto, o compliance é um ato de interesse público e não privado, por mais que este também seja realizado por pessoas jurídicas de direito privado.

Sérgio Shimura ensina que "a expressão "interesse público" evoca imediatamente a figura do Estado e mediatamente aqueles interesses que o Estado escolheu como mais

12 TONIN, Alexandre Baraldi. Compliance: Uma visão do compliance como forma de mitigação de responsabilidade. Revista dos Tribunais, Vol. 983. Ano.106. p.265-288. São Paulo, 2017. p.266.

${ }_{13}$ Art. 25. O edital deverá conter o objeto da licitação e as regras relativas à convocação, ao julgamento, à habilitação, aos recursos e às penalidades da licitação, à fiscalização e à gestão do contrato, à entrega do objeto e às condições de pagamento. $\$ \mathbf{4}^{\mathbf{0}}$ Nas contratações de obras, serviços e fornecimentos de grande vulto, o edital deverá prever a obrigatoriedade de implantação de programa de integridade pelo licitante vencedor, no prazo de 6 (seis) meses, contado da celebração do contrato, conforme regulamento que disporá sobre as medidas a serem adotadas, a forma de comprovação e as penalidades pelo seu descumprimento

${ }^{14}$ SHIMURA, Sérgio. Tutela Coletiva e sua efetividade. $1^{\text {a }}$ ed. Editora Método, São Paulo, 2006. p.46. 
relevantes, por consultarem aos valores prevalecentes na sociedade" ${ }^{15}$. Nota-se que a falta de cumprimento das ordens básicas do Estado pelos privados lesiona o erário de maneira difusa, a ponto de atingir pessoas de todas as esferas, sem ao certo conseguir individualizá-las, como é o caso da falta de verba para hospitais, escolas e segurança.

Porém, existem alguns motivos para que o compliance ainda não seja um fato social brasileiro, entre eles, o alto custo, a desinformação e a restrição quanto a forma de exploração econômica. Nota-se, ao mesmo tempo que o compliance é uma poderosa arma de investigação e transparência empresarial, possui o lado de restrição à empresa quanto a forma de sua exploração econômica, o que faz com que esta tente adequar tais ordenamentos jurídicos com a máxima efetividade de produção e lucro, todavia, nem sempre isso é possível, e é neste ponto que existe a colisão entre o compliance e os interesses privados da empresa.

O compliance também possui caráter preventivo, ou seja, não se trata de punir uma empresa pelo não cumprimento do regime jurídico local, mas de evitar que este não seja cumprido, uma vez que obriga a manutenção da ética e o cumprimento dos deveres legais. Desta forma, tenta-se adequar o capital sem prejudicar o social.

Para que tudo isso possua efetividade e viabilidade, deve a pessoa jurídica atuar em conjunto com o Estado e, nessa dicotomia "interesse empresarial" e "social", deve-se aplicar a função social da empresa onde visa estabelecer que a pessoa jurídica de direito privado ou público deve atuar de forma a respeitar suas finalidades, atuando com ética e honestidade.

\begin{abstract}
A função social da empresa não protege somente a pessoa jurídica contra atos ruinosos de seus sócios (impondo-se como poder-dever uma condução dos objetivos sociais compatíveis com o interesse da coletividade), senão também impondo ao poder público a preservação da atividade empresarial, tão necessária ao desenvolvimento econômico. A função social da empresa busca assegurar a ainda a utilização dos bens de produção segundo a sua função social, de modo que deverá haver, sob pena de violação a esse princípio, responsabilidade social na atividade empresarial. ${ }^{16}$
\end{abstract}

Existe uma dicotomia obrigacional entre a pessoa jurídica de direito privado e o Estado. Segundo Adriane Pires “o que se observa é um dinamismo da economia e as modificações das relações sociais e políticas oportunizam o surgimento de novas formas de comportamentos danosos, representando riscos para a sociedade" ${ }^{17}$. Assim, surge a necessidade de uma cooperação mútua nas atuações, a fim de evitar lesão oriunda de corrupção e demais delitos

\footnotetext{
${ }^{15}$ SHIMURA, Sérgio. Tutela Coletiva e sua efetividade. $1^{\text {a }}$ ed. Editora Método, São Paulo, 2006. p.26.

${ }^{16}$ CHAGAS, Edison Enedino das. Direito Empresarial - Esquematizado, $5^{\text {a }}$ ed. Saraiva, São Paulo. 2018. p. 53. ${ }^{17}$ PIRES, Adriane Pinto Rodrigues da Fonseca. Lavagem de capitais e delitos omissivos: responsabilidade penal pelo descumprimento dos deveres de compliance. $1^{a}$ ed. Juruá, Curitiba, 2015. p. 21/22.
} 
empresariais.

Deve-se aplicar, a função social da empresa, a chamada boa-fé objetiva, a qual adequase perfeitamente com o conceito de compliance, uma vez que aquela "impõe ao empresário e à sociedade empresária o dever de buscar a realização de seus interesses na exploração da atividade empresarial cumprindo rigorosamente a lei e adotando constante postura proba, leal, conciliatória e colaborativa ${ }^{18}$.

Pode-se entender que a natureza jurídica do compliance é de cooperação das empresas privadas com o Estado a fim de sanar eventuais necessidades investigativas, facilitando os procedimentos e participando ativamente para a elucidação e esclarecimento das dúvidas apontadas. Neste sentido é o entendimento de Guilherme Lobo Marchioni:

\begin{abstract}
O Acordo de Leniência na seara anticorrupção consiste em um pacto de cooperação de pessoas jurídicas com órgãos estatais, para fortalecimento de elementos capazes de contribuir com procedimentos investigativos referentes a infrações à Lei da Empresa Limpa, em troca de redução das sanções pecuniárias e restritivas de direito. Importa atentar que, além da obtenção de informações sobre ilícitos relevantes à investigação, também é escopo do Acordo de Leniência trazer a empresa à higidez ética, a fim de que a pessoa jurídica empreenda suas atividades com integridade ${ }^{19}$
\end{abstract}

E, neste mesmo sentido explica, novamente, Alexandre Baralci Tunin que a "atividade empresarial deve estar orientada por um ambiente de sustentabilidade, focada na concorrência leal e com princípios éticos, cujos empresários enquadram-se em um novo princípio denominado empresário-cidadão", e finaliza afirmando que "o compliance, que é compreendido como sinônimo de prevenção, pode assumir um importante papel na sociedade" 20 .

Ocorre que, dificilmente a corrupção por meio de lavagem de dinheiro, sonegação, suborno ou outros meios ocorrerá sem a participação ou ineficiência da fiscalização estatal, tanto que Stephen D. Morris e Charles H. Blake a definem como "abuse of trust, generally one involving public power, for private benefits which often, but by no mean always, come in the form of Money"21. A Corrupção é oriunda de um governo fraco, sem transparência ou política de $\operatorname{poder}^{22}$.

\footnotetext{
${ }^{18}$ CHAGAS, Edison Enedino das. Direito Empresarial - Esquematizado, $5^{\text {a }}$ ed. Saraiva, São Paulo. 2018. p. 58. ${ }^{19}$ MARCHIONI, Guilherme Lobo. Protagonismo isolado da ISO 19600 em compliance não é apropriado. Disponível em: https://www.conjur.com.br/2016-jul-29/guilherme-lobo-protagonismo-iso-compliance-naoapropriado. Acesso em 04 de mar.2019.

20 TONIN, Alexandre Baraldi. Compliance: Uma visão do compliance como forma de mitigação de responsabilidade. Revista dos Tribunais, Vol. 983. Ano.106. p.265-288. São Paulo, 2017. p. 269.

${ }^{21}$ Morris, Stephen D. e Blake, Charles H., Corruption \& Politics in latin américa - National \& regional dynamics. Ed. Lynne Rienner Publishers, inc. Colorado. 2010.

${ }^{22}$ CAMPOS, J. Edgard e PRADHAN, Sanjay. The many faces of corruption - tracking vulnerabilities at the
} 
Ensina-se, corretamente, que aplicação do compliance não é de exclusividade dos órgãos diretores da empresa, mas trata-se de uma política interna onde todos os funcionários e envolvidos devem atuar em sincronia com as tais normas, uma vez que caso isso não ocorra a própria efetividade do compliance estará em jogo. É necessário, portanto, uma atuação da empresa em forma de célula e não por partes, trata-se da cumplicidade da pessoa jurídica e não apenas de seus sócios.

É necessário a criação periódica de instrumentos fiscalizatórios internos, colocando a investigação deste campo também na mão da pessoa jurídica de direito privado, uma vez que este, internamente, consegue de maneira muito mais eficaz colher provas e verificar atos do que a polícia ou o Ministério Público que estão, naturalmente, do lado de fora, facilitando inclusive a individualização da responsabilidade de cada agente envolvido na questão apresentada.

Por fim, aponta-se que a sanção a ser aplicada pelo órgão de compliance deve ser feita também em face da pessoa jurídica e não exclusivamente em face do agente interno causador do dano. Para a doutrina majoritária, essas sanções deveriam ter um cunho administrativo, com aplicações de multas e restrições empresariais. Todavia, para uma corrente minoritária deve-se aplicar a responsabilidade criminal para as pessoas jurídicas pelos crimes de corrupção, em analogia aos crimes ambientais, neste sentido afirma Guilherme de Souza Nucci ${ }^{23}$.

Porém, o presente trabalho não coaduna com tal entendimento, não devendo-o prosperar, uma vez que não se pode aplicar analogia in malam partem no ordenamento jurídico brasileiro, devendo apenas ser utilizada na hipótese favorável ao réu.

Assim, pode-se concluir que as sanções aplicadas às pessoas jurídicas por corrupção devem ser administrativas e civis e aos agentes internos sanções devem ser administrativas, cíveis e penais.

\section{INTRODUÇÃO}

A terra ocupa um papel de destaque na sociedade e sua ocupação, destinação e regulação é quase tão antiga quanto a própria história da humanidade (MACHADO, 2017). Globalmente, mais de 1,6 bilhão de pessoas vivem em moradias inadequadas, enquanto mais de 100 milhões estão desabrigadas (CHAUNDHRY, 2019).

sector level. $1^{\text {a }}$ ed. The World Bank, Washington, 2007. p. 361.

${ }^{23}$ NUCCI, Guilherme de Souza. Corrupção e anticorrupção. Ed. Forense, Rio de Janeiro, 2015. p.88. 


\section{COMPLIANCE E A CORRUPÇÃO NA AMÉRICA LATINA}

A corrupção tem sua base social fomentada no princípio humano básico da reciprocidade e tem seu conceito mudado através dos tempos, mas encontra-se presente entre os seres humanos em toda sua história, como demonstrado em passagens históricas clássicas, como as oferendas às entidades no antigo Egito, traição de Judas, as punições contatas por Dante em "inferno", o julgamento de Francis Bacon, o caso Watergate entre outros. Porém, o que todos esses casos possuem em comum é que o ato praticado visa a obtenção de algo de maneira oblíqua ao caminho devido, ou seja, afronta-se a moral social em uma reciprocidade, sem a qual o objetivo final não teria sido atingido.

Nota-se que o suborno não se confunde com o termo corrupção, uma vez que aquele é um ato que dá ensejo à este, porém, deve ser trabalhado e analisado no presente momento de maneira em destaque, tendo em vista, que muitos atos de corrupção são feitos por meio de suborno, sendo assim, nas palavras de John Noonan, "o suborno é um ato que só se distingue de outras reciprocidades se identificado e condenado socialmente"24

Neste diapasão o Compliance é um grande aliado ao combate a corrupção, inclusive, combate a corrupção internacional, uma vez que visa uma atuação sem fronteiras, de maneira cosmopolita, a fim de atuar perante todas as empresas nacionais e multinacionais. Evidencia-se que, não haveria eficácia do compliance nas medidas contra a corrupção, caso uma empresa com sede em diversos países devesse cumprir as regras em apenas alguns desses.

Como demonstrado, houve o pioneirismo dos Estados Unidos no combate a corrupção das empresas por meio de compliance, especialmente com a edição da foreing corrupt pratice act, a qual vem com o viés de combate a corrupção empresarial, focada nas práticas de suborno $^{25}$.

Já a Europa criou em 1999 a chamada "convenção penal sobre corrupção do conselho da Europa", porém, na américa latina, por mais que os países venham tratando do conceito de compliance em seus territórios, ainda é embrionária perto dos estudos norte-americanos e europeus, sendo necessário adequar a realidade latina à aplicabilidade do compliance, o que ainda não ocorreu.

Em 2014, a International Organization for Standardization formulou o ISO 19600 (Compliance management systems - Guide-lines) a qual visa promover e estabelecer um guia

\footnotetext{
${ }^{24}$ NOONAN JR. John T., Subornos, Tradução: Elsa Martins, $1^{a}$ ed., Rio de Janeiro: Editora Bertrand Brasil S.A., 1989. p. 03/04.

25 Foreign Corrupt Practices Act - Disponível em: https://www.govinfo.gov/content/pkg/STATUTE91/pdf/STATUTE-91-Pg1494.pdf . Acesso em: 06 mar. 2019.
} 
para a formação e utilização do compliance nos ambientes empresariais ${ }^{26}$. Em 2016 publicou a ISO 37001 (anti-bribery management system) sendo um dos programas de combate a corrupção muito bem desenvolvido, trabalhando, especificadamente, a modalidade de corrupção pelo suborno, inclusive com o conceito deste. Assim, entende-se que suborno seja

\begin{abstract}
“(...) oferta, promessa, entrega, aceitação ou solicitação de uma vantagem indevida de qualquer valor, que pode ser financeiro ou não financeiro, direta ou indiretamente, e independente de posição, em violação às leis aplicáveis, como um incentivo ou recompensa para uma pessoa que está agindo ou deixando de agir, em relação ao desempenho das funções daquela pessoa"27.
\end{abstract}

Um dos grandes problemas da corrupção na América Latina é a dificuldade que o Estado, em muitas vezes, tem de encontrar e analisar o problema, ou porque o próprio Estado encontra-se envolvido na corrupção e não o quer fazer, ou porque as empresas camuflam sua informações para burlar a devida fiscalização, neste sentido Steve Morris e Charles Blake dizem que "This obscurity makes if difficult to collet systematic evidence, assess the true levels of corruption within a country, differentiate the many types of corruption, or compare corruption among a country or across the time" ${ }^{28}$. Assim o compliance na América Latina ainda é mais um aspecto formal do que real, a qual tenta a todo custo levantar-se e sair do estigma de países em desenvolvimento para países desenvolvidos.

É necessário um estudo do bloco da América Latina como aplicador do compliance, uma vez que todos são muito semelhantes tendo em vista suas culturas, blocos econômicos e tempo de existência, nesse diapasão entende-se que

Todo esse processo de transformação do modo como se faz negócios na américa latina, passa, necessariamente, pela existência de um ambiente regulatório que seja capaz de investigar e punir, de maneira adequada, empresas, indivíduos e funcionários públicos envolvidos em práticas ilícitas. Cada país tem a sua história e desafios bastante singulares. Mas, de forma geral, todos seguem um script semelhante. e isso acontece até pelo fato de todas serem democracias bastante jovens. ${ }^{29}$

Um estudo realizado pela Transparency International ${ }^{30}$ demonstra que a América Latina

\footnotetext{
${ }^{26}$ ANSELMO, Márcio Adriano. Compliance, direito penal e investigação criminal: uma análise à luz da ISSO 19600 e 37001, Revista dos Tribunais, vol. 979, ano 106. p.53-67. São Paulo: Ed RT, 2017. p. 59.

27 ANSELMO, Márcio Adriano. Compliance, direito penal e investigação criminal: uma análise à luz da ISSO 19600 e 37001, Revista dos Tribunais, vol. 979, ano 106. p.53-67. São Paulo: Ed RT, 2017. p. 60.

${ }_{28}$ Morris, Stephen D. e Blake, Charles H., Corruption \& Politics in latin américa - National \& regional dynamics. Ed. Lynne Rienner Publishers, inc. Colorado. 2010. p.5.

${ }_{29}$ SIBILLE, Daniel e KALAY, Marcio EL. Compliance na América Latina - República Argentina, Brasil, Chile, Colômbia, Guatemala, México e Peru. - Disponível em: https://d335luupugsy2.cloudfront.net/cms/files/28354/1533056778Compliance_na_Amrica_Latina.pdf Acesso 09 mar. 2019. p. 5.

${ }^{30}$ Transpararency Internacional - Disponível em: https://www.transparency.org/cpi2018. Acesso em: 06 mar.
} 
e a África possuem os maiores índices de corrupção mundial, sendo que em uma escala de 0 até 100 , onde 0 é o índice de maior corrupção e 100 o índice de menor corrupção, o Brasil possui a pontuação $35 / 100$, estando em $105^{\circ}$ de 180 países analisados.

Sendo que na América latina o Chile e o Uruguai tomam a frente em países menos corruptos, sendo 67/100 e 70/100 a pontuação dos respectivos.

Não é por menos que o Chile possui uma posição tão bem classificada, a segunda melhor de toda América latina, ele foi o primeiro país da América do Sul que estabeleceu normas contra a corrupção.

O Chile possui desde 2009 a lei $n^{\circ} 20.393$ que institui responsabilidade penal para as pessoas jurídicas de direito privado e público, a fim de punir, fiscalizar e evitar a lavagem de dinheiro, o financiamento ao terrorismo, os subornos entre outras formas de corrupção.

\footnotetext{
Um aspecto bastante interessante do mercado chileno é que a Lei $\mathrm{N}^{\circ} 20.393$, que trata da responsabilidade penal das pessoas jurídicas, permite que empresas certificadoras independentes façam a análise dos programas de integridade das empresas, e que, de acordo com os requisitos da lei, os aprovem ou sugiram melhorias que possam ser integradas a eles. A certificação é bastante reconhecida e tem impulsionado o mercado a elevar os seus padrões de integridade. ${ }^{31}$
}

Nota-se que o Chile caminha adequando o combate da corrupção com o instrumento do compliance e os resultados são cientificamente demonstrados.

Em 2011, a Colômbia passou a ter a sua primeira lei antissuborno; anteriormente, somente o código penal colombiano dispunha a tipificação do crime de corrupção de funcionários públicos. Mas foi somente em 2016 que foi promulgada a lei ${ }^{\circ}$ 1.778/16, chamada de "lei de corrupção transnacional", tal norma visa fomentar a lei antissuborno, adequar-se à Organização para a Cooperação e Desenvolvimento Econômico e responsabiliza a pessoa jurídica privada por subornos com funcionários públicos.

Por fim, tal lei visa incentivar a aplicação do compliance nas empresas privadas, estabelecendo que elas possuam um crédito ao atuarem com programas de conformidade adequados, mitigando-se o valor quando da aplicação de multas por violações nacionais e estrangeiras ${ }^{32}$

2019.

${ }^{31}$ SIBILlE, Daniel e KALAY, Marcio EL. Compliance na América Latina - República Argentina, Brasil, Chile, Colômbia, Guatemala, México e Peru. - Disponível em: https://d335luupugsy2.cloudfront.net/cms/files/28354/1533056778Compliance_na_Amrica_Latina.pdf Acesso 09 mar. 2019. p.9.

${ }^{32}$ SIBILlE, Daniel e KALAY, Marcio EL. Compliance na América Latina - República Argentina, Brasil, Chile, Colômbia, Guatemala, México e Peru. - Disponível em: https://d335luupugsy2.cloudfront.net/cms/files/28354/1533056778Compliance_na_Amrica_Latina.pdf Acesso 09 mar. 2019. p.10. 
Seguindo-se a lista de países da América Latina, deve-se trazer que a Venezuela, por sua vez, é atualmente o país mais corrupto da América Latina e um dos mais corruptos do mundo, com pontuação $18 / 100$, ficando na $168^{\text {a }}$ posição de 180 países, permanecendo a frente apenas de países como Somália e Sudão. ${ }^{33}$.

Vale mencionar que na América Central o país com menor índice de corrupção é a Costa Rica que possui pontuação de 56/100.

Nota-se que na maioria destes países aplica-se um regime democrático de direito, o que é totalmente incompatível com a ideia de corrupção. Entende-se que em um estado democrático de direito, as eleições, verbas públicas, os valores do erário, entre outros são assuntos de livre acesso para toda a população, a fim de utilizar-se do princípio da publicidade para possibilitar que o cidadão atue como fiscal dos atos públicos. Sendo que a fiscalização pública é uma das principais maneiras de se evitar corrupções, como anteriormente mencionado. Desde a revolução francesa, Honoré Mirabeau já conceituava que poderiam lhe dar o julgamento que fosse, com qualquer juiz, mas que tudo que o fizesse, fosse feito em público. Neste caminhar também está o entendimento de Steve Morris e Charles Blake "The bulk of guiding reserch questions in the field tend to emphasize the theoretical incompatibility of democracy and corruption" 34 .

Na Argentina, ainda sobre a evolução latina do compliance, foi publicada a resolução anticorrupção de número 27.401/2018, que visa uma maior aplicabilidade do instituto nas empresas, com diversas proibições e mandamentos a fim de estabelecer a ética e honestidade. Tal norma estabelece uma possibilidade de responsabilidade criminal e administrativo da pessoa jurídica em casos de subornos domésticos, transnacionais, tráfico de influência, enriquecimento ilícito de servidores, assim como a aplicação de multa de até 05 (cinco) vezes o benefício financeiro indevido obtido ${ }^{35}$.

A norma recebeu o nome de lei de responsabilidade penal empresarial e está sendo estimulada pelo atual governo com o objetivo de tornar o país membro da organização para a cooperação e desenvolvimento econômico (OCDE).

Além de evitar prejuízo ao erário, a aplicação do compliance na Argentina vem sendo

\footnotetext{
${ }^{33}$ Transpararency Internacional - Disponível em: https://www.transparency.org/cpi2018. Acesso em: 06 mar. 2019.

${ }^{34}$ MORRIS, Stephen D. e BLAKE, Charles H., Corruption \& Politics in latin américa - National \& regional dynamics. Ed. Lynne Rienner Publishers, inc. Colorado. 2010. p.18.

${ }^{35}$ SIBILLE, Daniel e KALAY, Marcio EL. Compliance na América Latina - República Argentina, Brasil, Chile, Colômbia, Guatemala, México e Peru. $\quad-\quad$ Disponível em: https://d335luupugsy2.cloudfront.net/cms/files/28354/1533056778Compliance_na_Amrica_Latina.pdf Acesso 09 mar. 2019. p.6.
} 
efetivada de maneira a fomentar inclusive a economia local; é o que entende Daniel Sibille e Márcio El Kalay:

\begin{abstract}
Assim como ocorreu no Brasil, outro reflexo positivo da entrada em vigor da nova legislação anticorrupção argentina é a valorização dos profissionais de compliance. Estimativas dão conta de que sejam criados ao menos cinco mil novos postos de trabalhos na área por lá, mantendo o mercado na região bastante aquecido.
\end{abstract}

No México a situação é também muito recente e possui uma agravante em relação aos demais países apresentados até então, o Ministério Público mexicano não possui autonomia, para que livremente efetue as investigações nos casos de corrupção das pessoas jurídicas.

Em julho de 2016, o presidente Erique Peña Nieto anunciou a aprovação de mudanças radicais nas leis anticorrupção do México. As novas medidas foram o ponto culminante de um processo plurianual, que se originou com uma petição cidadã, a partir do trabalho de grupos da sociedade civil. Esses esforços de base resultaram em reformas constitucionais em 2015, e as leis aprovadas em 2016 representam a implementação estatutária destas. Entre o que é proposto pelas novas leis e as revisões da legislação já existente, há disposições para criar a figura do promotor independente da corrupção e fortalecer as proteções aos denunciantes, além de mecanismos para robustecer a cooperação entre as diferentes esferas do governo ${ }^{36}$.

Diferentemente do Peru, onde "semelhante à lei proposta pela Argentina, a lei de corrupção corporativa do Peru, aprovada em março de 2016, estabelece a responsabilidade objetiva para empresas públicas e privadas responsáveis pelo suborno" isso ocorre independentemente de o agente ter ou não sofrido processo $^{37}$. Porém benéfico mencionar que o art. 41 da Constituição Mexicana foi alterado, em 2017, para tornar imprescritível os crimes de corrupção.

Já a Guatemala é um dos países menos desenvolvidos da América Latina, sendo que a aplicação do Compliance ainda muito superficial, todavia, pune-se com pena privativa de liberdade e pecuniária os crimes de corrupção praticados, conforme redação dada pelo art. 155 do código penal modificado em 2012. E por meio do seu art. 38 do código penal estabelece a responsabilidade às pessoas jurídicas nos casos de corrupção.

Por fim, no Brasil houve o marco inicial do compliance, quando tenta-se adequar ao sistema internacional. Assim, ele surge em 1998, com a publicação da lei no 9.613 (lei de

\footnotetext{
${ }^{36}$ SIBILlE, Daniel e KALAY, Marcio EL. Compliance na América Latina - República Argentina, Brasil, Chile, Colômbia, Guatemala, México e Peru. https://d335luupugsy2.cloudfront.net/cms/files/28354/1533056778Compliance_na_Amrica_Latina.pdf Acesso 09 mar. 2019. p. 11.

${ }^{37}$ SIBILLE, Daniel e KALAY, Marcio EL. Compliance na América Latina - República Argentina, Brasil, Chile, Colômbia, Guatemala, México e Peru. - Disponível em: https://d335luupugsy2.cloudfront.net/cms/files/28354/1533056778Compliance_na_Amrica_Latina.pdf Acesso 09 mar. 2019. p. 12.
} 
lavagem de dinheiro), sendo que esta lei criou o Conselho de Controles das Atividades Financeiras - COAF, a fim de fiscalizar e as atividades de empresas suspeitas. Tal lei, ainda, tipificou o crime de lavagem de dinheiro para os agentes envolvidos ${ }^{38}$.

Posteriormente, foi publicada no Brasil a norma 12.846/13 a qual instituiu um programa de anticorrupção. Todavia, este somente possuiu maior efetividade após a operação lava-jato, quando as empresas começaram a se adequar com o compliance, como exemplo, a própria Petrobrás que atualizou seu programa de "questionário de integridade" preenchidos pelos seus funcionários, os quais compulsoriamente devem fazê-lo sob pena de não atenderem mais as normas da companhia ${ }^{39}$.

Outras normas brasileiras que fomentam a criação e desenvolvimento do compliance, são a norma estadual do Rio de Janeiro $n^{\circ} 7.753 / 17$ e a norma do Distrito Federal $n^{\circ}$ 6.112/18, em ambas determinam que as pessoas jurídicas somente poderão realizar negócios jurídicos com as unidades federativas, caso possuam "programas de integridade", ou seja, que desenvolvam e mantenham um programa de compliance ${ }^{40}$.

E por fim, como mencionado, a nova lei de licitações e contratos administrativos, a lei $\mathrm{n}^{\circ} 14.133 / 21$ que visa a necessidade de as pessoas jurídicas implementarem compliance de maneira efetiva sempre que estiverem atuando com as pessoas jurídicas de direito público.

O compliance é um instrumento de combate direto todos esses tipos de corrupção, uma vez que visa aplicar de "dentro para fora" a manutenção e máxima clareza possível de seu funcionamento interno, ou seja, um benefício não somente para o Mercosul, mas para toda a américa latina.

Vale ressaltar que, é necessário a aplicação internacional do compliance para que a corrupção corporativa seja evitada ou reduzida ao máximo, principalmente quando tratar-se de empresas multinacionais ou nacionais de importação ou exportação.

Neste ponto existe uma colisão entre a necessária publicidade e os segredos empresariais e/ou técnicas de produção, porém quando se aplica o princípio da prevalência do interesse público sobre o particular, deve-se respaldar em preservar os interesses públicos, devendo as

\footnotetext{
${ }^{38}$ ANSELMO, Márcio Adriano. Compliance, direito penal e investigação criminal: uma análise à luz da ISSO 19600 e 37001, Revista dos Tribunais, vol. 979, ano 106. p.53-67. São Paulo: Ed RT, 2017. p. 57.

${ }^{39}$ SIBILLE, Daniel e KALAY, Marcio EL. Compliance na América Latina - República Argentina, Brasil, Chile, Colômbia, Guatemala, México e Peru. - Disponível em: https://d335luupugsy2.cloudfront.net/cms/files/28354/1533056778Compliance_na_Amrica_Latina.pdf Acesso 09 mar. 2019. p. 7.

${ }^{40}$ SIBILLE, Daniel e KALAY, Marcio EL. Compliance na América Latina - República Argentina, Brasil, Chile, Colômbia, Guatemala, México e Peru. - Disponível em: https://d335luupugsy2.cloudfront.net/cms/files/28354/1533056778Compliance_na_Amrica_Latina.pdf. Acesso 09 mar. 2019. p. 8.
} 
empresas manter sua transparência e preservar ao mesmo tempo sua independência e liberdade de trabalho, aplicando sempre o compliance o qual já se mostrou uma poderosa arma a favor de toda sociedade.

Um dos maiores casos de corrupção da América Latina foi em território brasileiro com ramificações em países como Bolívia e Venezuela, entre outros. O Ministério Público Federal denunciou diversos diretores da Petrobrás e políticos pelo desvio de verba pública nos contratos firmados da empresa com outras empresas. O valor do suborno variava de $1 \%$ até $5 \%$ do valor dos contratos firmados, os quais eram na casa de bilhões de reais ${ }^{41}$.

Para que se tenha a ideia do escárnio que a corrupção brasileira chegou, observe que existem cartéis que monopolizam a maioria das licitações nacionais. A Petrobrás é o exemplo claro e habitual.

\begin{abstract}
Os preços oferecidos à Petrobrás eram calculados e ajustados em reuniões secretas nas quais se definia quem ganharia o contrato e qual seria o preço, inflado e benefícios privados e em prejuízo dos cofres estatais. $\mathrm{O}$ cartel tinha até um regulamento, que simulava regras de um campeonato de futebol, para definir como as obras seriam distribuídas. Para disfarçar o crime, o registro escrito da distribuição de obras era feito, por vezes, como se fosse a distribuição de prêmios de um bingo ${ }^{42}$.
\end{abstract}

No caso da "operação lava-jato" foi fortificado o compliance com a utilização das colaborações premiadas, onde muitos funcionários começaram a levar até conhecimento das autoridades locais, as informações oriundas dos desvios de verba, superfaturamento, suborno e outros.

A necessidade de se combater a corrupção não é assunto recente, sendo esta oriunda desde da formação da sociedade, mas com a evolução humana entende-se que haja a necessidade de um controle social para a adequada manutenção da sociedade.

O individualismo não pode mais fazer parte de nossa sociedade, mesmo que seja da natureza humana em muitas vezes isolar-se, inclusive pelas pessoas jurídicas. Primo Levi dizia que "a capacidade humana de cavar-se uma toca, de criar uma casca, de erguer ao redor de si uma tênue barreira defensiva, ainda que em circunstâncias aparentemente desesperadas, é espantosa e mereceria um estudo profundo" ${ }^{43}$. Ora tais barreiras e castas devem ser retiradas na exata medida entre a transparência e a proteção da individualidade.

\footnotetext{
${ }^{41}$ SILVEIRA, Renato de Mello Jorge. Compliance e direito penal na era pós-lava jato. Revista dos Tribunais. Vol. 979. Ano 106, p.31-52, São Paulo, 2017. p. 33.

${ }^{42}$ SILVEIRA, Renato de Mello Jorge. Compliance e direito penal na era pós-lava jato. Revista dos Tribunais. Vol. 979. Ano 106, p.31-52, São Paulo, 2017. p. 33.

${ }^{43}$ LEVI, Primo. É isto um homem? 2a ed. Rocco, Rio de janeiro, 2013. p.48.
} 
Por fim, vale mencionar que a corrupção intrínseca nas pessoas jurídicas de direito público e privado exerce um mal social extremamente grave, uma vez que licitações são fraudadas, ficais são subornados ou desvio de verbas do erário são feitos, os instrumentos públicos de manutenção da sociedade não irão se manter, ou se manterão a "trancos e barrancos", como são os casos dos hospitais públicos brasileiros ou das escolas públicas brasileiras.

As consequências da corrupção difusas como já apresentado, portanto, são pessoas morrendo em filas intermináveis de hospitais, crianças sem estudo ou qualquer tipo de amparo por parte do Estado e, em muitas vezes, a sua consequente marginalização.

Apresenta-se em toda América Latina um costume contra legem de inversão de valores, onde o habitual é a corrupção, ignorando sua catastrófica consequência. Esta corrupção não é elaborada apenas por mentes privilegiadas ou malfeitores estereotipados, mas, como explica Hannah Aredent, o mal é banal ${ }^{44}$, elaborado por pessoas comuns em seus dias normais, não necessitando de condições especiais para isso, apenas a oportunidade.

Com isso concluir-se-á, que se deve aplicar e exigir a eficácia do compliance como importante instrumento de apoio ao combate à corrupção na América Latina, a fim de evitar que os prejuízos sociais que em muitos casos são irreparáveis.

\section{CONCLUSÃO}

Ex positis, veio o presente trabalho apresentar que o instituto do compliance tem como foco central programas de combate e diminuição da corrupção sistêmica que existe entre pessoas de direito privado ou público com demais entes. Foi demonstrado que, tal instituto é instrumento social de transparência, ética e adequação com as normas do estado, a fim de evitar vários tipos de corrupção, como lavagem de dinheiro, subornos, fraudes fiscais, entre outros.

Fora contextualizado igualmente que o compliance somente possuirá efetividade caso haja a atuação da pessoa jurídica de direito privada ou pública conjuntamente com a atuação positiva do Estado, uma vez que não será possível que tal instrumento seja eficaz se o próprio Estado é parte ativa da corrupção inerente.

Demonstrou-se que o compliance começou a ser efetivamente desenvolvido na década de 70, do século passado, tendo sua origem os Estados Unidos da América, onde lançou Foreign Corrupt Practices Act, sendo que posteriormente a Europa adotou diversos meios de implementação do compliance, criado as normas de gestão de compliance (ISO 19600:2014) e

${ }^{44}$ ARENDT, Hannah. Eichmann em Jerusalém. 1ª ed. Companhia das letras, São Paulo. 1999. 
norma anticorrupção (ISO 37001:2016); porém somente teve início no Brasil na década de 90, quando publicou-se a lei $\mathrm{n}^{\circ} 9.613 / 98$ e posteriormente a lei $\mathrm{n}^{\circ} 12.846 / 13$.

Foi abrangido também que o compliance adequa-se perfeitamente a função social da empresa e a boa-fé objetiva, uma vez que visa atuar com moralidade, legalidade e transparência, dando a possibilidade da fiscalização das empresas pelos devidos órgãos competentes e pela própria população.

Com isso foi analisada a aplicabilidade do compliance às pessoas jurídicas da América Latina, evidenciando-se a real necessidade de uma aplicação internacional, principalmente nos países com maior índice de corrupção como o Brasil, Venezuela e Bolívia. E evidenciou-se que os países com melhor desenvolvimento econômico- social, e menor índice de corrupção utilizam-se do complicance como instrumento de fiscalização, como Chile e Uruguai.

Assim por mais que a América Latina ainda não possuía o desenvolvimento em compliance, como os Estados Unidos ou a Europa, ela caminha em bons passos aplicando normas internas, a fim de requerer a forma cooperativa das pessoas jurídicas de direito público ou privado, trazendo assim maior ética, transparência e fiscalização, ajudando que o erário seja cada vez menos corrompido, para que seja este devidamente aplicado em prol a sociedade, com seus devidos fins.

\section{REFERÊNCIAS}

ANSELMO, Márcio Adriano. Compliance, direito penal e investigação criminal: uma análise à luz da ISSO 19600 e 37001, Revista dos Tribunais, vol. 979, ano 106. p.53-67. São Paulo: Ed RT, 2017.

ARENDT, Hannah. Eichmann em Jerusalém. $1^{a}$ ed. Companhia das letras, São Paulo. 1999.

CAMPOS, J. Edgard e PRADHAN, Sanjay. The many faces of corruption - tracking vulnerabilities at the sector level. $1^{\text {a }}$ ed. The World Bank, Washington, 2007.

CANOTILHO, José Joaquim Gomes. Direito constitucional e teoria da Constituição. $7^{\mathrm{a}}$ ed. Coimbra, Almedina. 2003.

CHAGAS, Edison Enedino das. Direito Empresarial - Esquematizado, $5^{\text {a }}$ ed. Saraiva, São Paulo. 2018.

Foreign Corrupt Practices Act - Disponível em:

https://www.govinfo.gov/content/pkg/STATUTE-91/pdf/STATUTE-91-Pg1494.pdf . Acesso em: 06 mar. 2019.

Foreign Corrupt Practices Act, Disponível em : < https://www.justice.gov/criminalfraud/fcpa-resource-guide > , Acesso em 11 de nov. 2020. 
KANT, Immanuel. Crítica da Razão Prática, $3^{\text {a }}$ ed., São Paulo: Martin Claret, 2011. p. 31.

Lei anticorrupção - Disponível em: <http://www.planalto.gov.br/CCIVIL_03/_Ato20112014/2013/Lei/L12846.htm>. Acesso em: 05 mar. 2019.

LEVI, Primo. É isto um homem? 2a ed. Rocco, Rio de janeiro, 2013.

MARCHIONI, Guilherme Lobo. Protagonismo isolado da ISO 19600 em compliance não é apropriado. Disponível em: https://www.conjur.com.br/2016-jul-29/guilherme-loboprotagonismo-iso-compliance-nao-apropriado. Acesso em 04 de mar.2019.

Morris, Stephen D. e Blake, Charles H., Corruption \& Politics in latin américa - National \& regional dynamics. Ed. Lynne Rienner Publishers, inc. Colorado. 2010.

NUCCI, Guilherme de Souza. Corrupção e anticorrupção. Ed. Forense, Rio de Janeiro, 2015.

NOONAN JR, John T., Subornos, Tradução Elsa Martins, 1a ed., Rio de Janeiro: Editora Betrand Brasil S.A., 1984. p. 589.

PIRES, Adriane Pinto Rodrigues da Fonseca. Lavagem de capitais e delitos omissivos: responsabilidade penal pelo descumprimento dos deveres de compliance. $1^{\mathrm{a}}$ ed. Juruá, Curitiba, 2015.

SILVEIRA, Renato de Mello Jorge. Compliance e direito penal na era pós-lava jato. Revista dos Tribunais. Vol. 979. Ano 106, p.31-52, São Paulo, 2017.

SARLET, Ingo Wolfgang. Dignidade da Pessoa Humana e Direitos Fundamentais na constituição federal de 1988. $9^{\text {a }}$ ed. Livraria do advogado, Porto Alegre, 2012.

SHIMURA, Sérgio. Tutela Coletiva e sua efetividade. $1^{\mathrm{a}}$ ed. Editora Método, São Paulo, 2006.

SIBILlE, Daniel e KALAY, Marcio EL. Compliance na América Latina - República Argentina, Brasil, Chile, Colômbia, Guatemala, México e Peru. - Disponível em: https://d335luupugsy2.cloudfront.net/cms/files/28354/1533056778Compliance_na_Amrica_L atina.pdf Acesso 09 mar. 2019.

TONIN, Alexandre Baraldi. Compliance: Uma visão do compliance como forma de mitigação de responsabilidade. Revista dos Tribunais, Vol. 983. Ano.106. p.265-288. São Paulo, 2017.

Transpararency Internacional - Disponível em: https://www.transparency.org/cpi2018. Acesso em: 06 mar. 2019. 